\title{
Issues and Options for Improving Services for Diverse Populations
}

\author{
Kwame McKenzie \\ Centre for Addiction and Mental Health
}

\begin{abstract}
International migration has led to increasingly diverse populations in many high-income countries. With approximately 250,000 newcomers each year, it should be no surprise that developing services that meet the needs of immigrants, refugees, ethnocultural, and racialized populations (IRER) is a major priority in the Mental Health Strategy for Canada. The published Canadian literature on the mental health of diverse populations concludes that differences in the exposure to social risk factors lead to differences in rates of illness for some groups. Whether rates of illness are high or low in a particular group, however, problems in accessing services are ubiquitous. Improving the service response will require political will, leadership, strategic planning, and data, and must include people with lived experience and the populations at highest risk. This paper outlines the "Issues and Options" paper commissioned by the Mental Health Commission of Canada, which used a thorough literature review and a national consultation to develop a model for service development. A health equity approach that utilizes local-population-based planning and the evidence-based interventions that are available for diverse groups could improve services for IRER groups in Canada.
\end{abstract}

Keywords: culture, ethnicity, immigration, refugee, racialized, health equity, rates of illness, social risk, health policy, community-based planning

\section{RÉSUMÉ}

Les migrations internationales ont eu pour effet de diversifier de façon de plus en plus importante la population de plusieurs pays à revenu élevé. Comme le Canada reçoit environ 250000 nouveaux arrivants chaque année, il n'est pas surprenant que le développement de services qui répondent aux besoins des immigrants, des réfugiés et des membres de groupes ethnoculturels et racialisés soit une priorité de la

Kwame McKenzie, Health Equity Research, Centre for Addiction and Mental Health, Toronto, ON.

With kind acknowledgement to the MHCC Diversity Task Group: Emily Hansson (Research Coordinator), Andrew Tuck (Research Analyst), Janice Lam and Fatimah Jackson (research assistants). Also to task group members Howard Chodos, Kwasi Kafele, Laurence Kirmayer, Brenda Leung (Associate Research Officer), Ted Lo, Steve Lurie, Gillian Mulvale, Sri Pendakur, Adriana Reina, Aseefa Sarang, Miriam Stewart, and Robert Wright.

I would like to acknowledge those who participated and organized in both the in-person and electronic consultations for their invaluable input. I would also like to acknowledge those involved with the consumer focus groups. This includes those from Across Boundaries and the Canadian Mental Health Association Toronto Branch who organized and facilitated these groups as well as the participants in these groups.

Correspondence concerning this article should be addressed to Kwame McKenzie, Health Equity Research, Centre for Addiction and Mental Health, 80 Workman Way, Toronto, Ontario; (416) 535-8501 ext. 39150; kwame.mckenzie@camh.ca

doi:10.7870/cjcmh-2015-012

Published by Canadian Periodical for Community Studies Inc. 
stratégie en matière de santé mentale du pays. La recherche canadienne sur la santé mentale de diverses populations montre que des degrés d'exposition différents à des facteurs de risque sociaux conduisent à des taux de maladie différents dans certains groupes. Toutefois, que les taux de maladie soient élevés ou faibles dans un groupe donné, l'accès à des services reste un problème partout. L'amélioration de l'accès aux services exigera de la volonté politique, du leadership, de la planification stratégique et l'utilisation de données populationnelles, et le processus doit inclure des personnes ayant de l'expérience de telles situations ainsi que des représentants des populations à risque élevé. Dans cet article, je fais un compte rendu du rapport «Issues and Options » commandé par la Commission de la santé mentale du Canada, fondé sur une revue de la littérature et sur une consultation nationale, et dont l'objectif était de concevoir un modèle de développement des services. Une approche axée sur l'équité en matière de santé et qui est le résultat d'une planification basée sur la population locale et met de l'avant des interventions dont l'efficacité a été démontrée dans différents groupes pourrait permettre d'améliorer les services offerts aux immigrants, aux réfugiés et aux membres de groupes ethnoculturels et racialisés.

Mots clés : culture, appartenance ethnique, immigration, réfugiés, racialisation, équité en matière de santé, taux de maladie, risques sociaux, politiques de la santé, planification axée sur la collectivité

Improving services and outcomes for immigrant, refugee, ethnocultural, and racialized groups (IRER), is a common challenge for mental health systems in high-income countries. Increased rates of illness, poorer access to care and care outcomes, and poorer satisfaction with services have been reported in these groups in Canada and internationally. Canada is becoming more ethnically diverse each year because immigration is the driver of population growth. The size of the population, rate of increase, and specific issues may differ in each province or territory, but all jurisdictions will have to meet the challenge of providing mental health services to their multicultural populations and develop health promotion strategies that improve the health status of IRER groups.

The Service Systems Advisory Committee of the Mental Health Commission of Canada (MHCC) established a project to consider the issues and options for service improvement for IRER groups and report to the commission. The aim was to help the commission's deliberations on which goals should be in the Mental Health Strategy for Canada. The project was influential in seeing diversity and health equity enshrined as fundamental principles in the vision of transformed mental health services in Canada.

The "Issues and Options" paper, as it became known, was the result of a number of different lines of investigation and consultation. An analysis of the data from the 2006 census, supplemented by available data from the provinces, was used to produce a statistical picture of Canada's IRER groups. A literature review of published papers was then performed with the guidance of a librarian specializing in mental health. These two sources of information and the experience and knowledge of a steering group of experts in multicultural health from across Canada were used to help develop a paper outlining the issues and some potential options for service improvement for IRER groups.

Consultation on this paper took a number of forms. The paper was posted on the websites of the Mental Health Commission of Canada and the Centre for Addiction and Mental Health. A survey was developed (using Survey Monkey) so that the public could give their opinions on the paper and more specifically on the options for service improvement. The electronic postings were widely advertised at face-to-face presentations and through the networks of the SSAC and the steering group, and other professional networks. The paper 
was sent to bodies that govern health in the provinces, territories, and cities, and to federal government offices involved in health in general and in the settlement and welfare of immigrants and refugees. The document was also sent out to advisory bodies within the Mental Health Commission of Canada.

Face-to-face focus groups of professionals, service providers, community organizations, and settlement and education services were undertaken in seven centres across Canada. Feedback from the face-to-face and electronic consultations was incorporated in the paper. Because people with lived experience of mental health problems and illnesses were underrepresented in the focus groups, extra focus groups specifically for this sector of the population were undertaken and the results incorporated in the paper. Finally, a diverse group of 35 people from across Canada, including some people who had taken part in the focus groups and representatives of bodies named in the document recommendations, were invited to Toronto for a day to review the near-final draft. Results of this meeting were shared with MHCC board and advisory committee members. Their views were included and this final draft was then sent back to the steering group and the SSAC for their review and approval. In addition to the literature, the views of over four hundred people were represented in the document.

"Issues and Options" was an attempt to fuse the data, the views of a diverse group of stakeholders, of people with lived experience and their families, and of governance bodies across Canada. It was not a protocol for service development but an outline of the issues that policy-makers, health planners, and service providers may find beneficial to consider when embarking on improving mental health services for IRER groups. The options section includes suggestions for service improvement as well as some examples of how these ideas are being implemented in various parts of Canada.

This paper gives a snapshot of Canadian medical history. It reflects the literature, the views of those involved in the psychiatric system either directly or peripherally, and the synthesis of the information by a group who were eventually successful in influencing policy in Canada.

"Issues and Options" was arranged in four sections, and this paper will follow those sections. Parts 1, 2, and 3 are the "Issues" sections of the paper, while Part 4 represents "Options":

1. The demography of Canada's immigrant, racialized, ethnocultural and refugee populations, definitions of terms and discussion of the model used to consider the development of (a) mental health problems and illnesses and (b) the pathways to getting care.

2. A synthesis of research into the mental health problems and illnesses of IRER populations, focusing on the Canadian literature.

3. An outline of previous national policy papers on improving Canada's mental health services for IRER populations.

4. A strategy for service development, recommendations, and examples of initiatives across Canada.

\section{DEMOGRAPHY, DEFINITIONS, AND PATHWAYS TO CARE}

\section{Canada's IRER Populations}

Canada is one of the most diverse countries in the world. Nearly $20 \%$ of the population was born outside Canada, and hundreds of thousands of new immigrants arrive each year (Statistics Canada, 2008a). In 
some parts of the country, visible minorities comprise over $40 \%$ of the population. Canada's future economic prosperity will depend in part on population growth, and currently Canada's main driver for growth is immigration, making immigrants an important national resource.

Until the 1960s, $90 \%$ of immigration to Canada was from Europe. Currently only $19 \%$ of immigrants arrive from Europe, and most immigrants come from south and east Asian countries. As Canada grows it is becoming more diverse, although the majority of people who identify themselves as belonging to minority groups are Canadian citizens. Some have been in Canada for centuries, but the majority are first- or secondgeneration Canadians (Statistics Canada, 2008d).

Canada's IRER populations mainly live in or around major cities, but there are significant rural populations as well. Every province and territory in Canada has an IRER population. They are different sizes, are growing at different rates, and come predominantly from different places. In some provinces and territories the population is small, but in others it is up to a quarter of all the people who live there.

These different trends in growth for IRER groups in different geographical locations offer a challenge for any mental health strategy. It needs to be flexible enough to be useful to areas with stable populations as well as ones where populations are growing rapidly. Any strategy has to meet the challenge of more populous areas as well as areas where IRER groups are a small proportion of residents.

\section{Mental Health Problems and Illnesses in IRER Groups}

Although other countries such as the United Kingdom and the United States have published extensively on the health and mental health of IRER groups, research in Canada has been fairly limited, but is now increasing. "Issues and Options" presented a dynamic model for the development of mental health problems in which significant life events, stresses, and vulnerabilities promoted mental health problems but coping strategies, resilience, and the social and medical safety net prevented them. This model is useful when considering not only how people develop poor mental health, or mental health problems and illnesses, but also what we can do about them.

There are many types of vulnerabilities, life events, and social stresses. Differences in the rates of mental illness and the risk of mental health problems and illness between IRER groups are due to the balance of stresses and resources that each group has available to them.

It should be emphasized that this pathway will reflect only one part of a person's existence. It captures a certain set of circumstances leading to the development of a particular mental health problem or illness. It is possible for an individual to develop a mental health problem or illness because of difficulties and vulnerabilities in one part of their life while still being mentally healthy in another part of their life and psychological functioning.

The model (Figure 1) gives an outline that helps us to understand how changes in risk increase the chance of a person developing mental health problems and illnesses that need care. It also gives a framework for understanding public, private, and voluntary sector initiatives aimed at improving how IRER communities could promote mental health as well as decrease the rates of mental health problems and illnesses. 


\section{Figure 1}

\section{Development of Mental Health Problems and Promotion of Mental Health in IRER Communities}

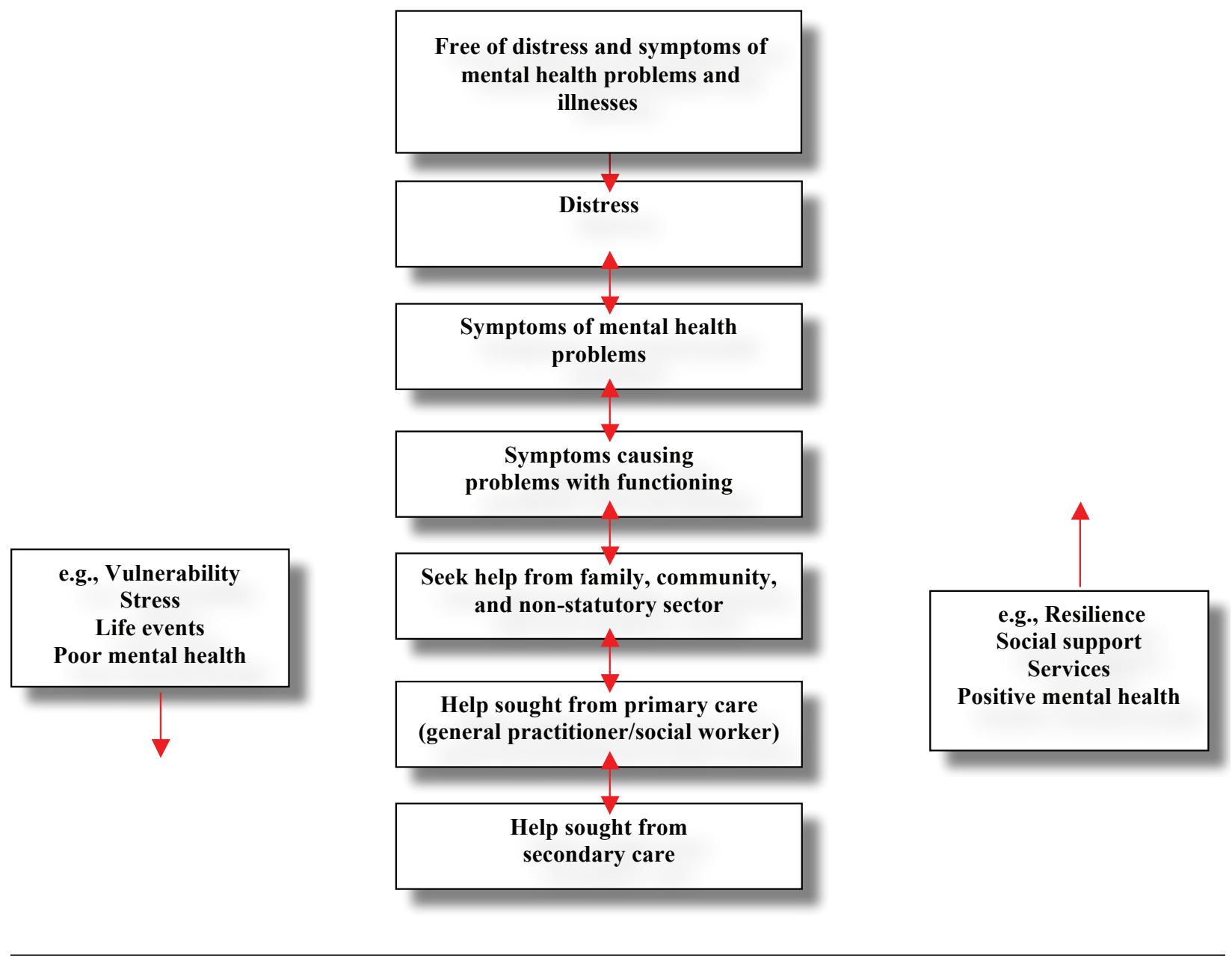

\section{RESEARCH STUDIES INTO MENTAL HEALTH AND MENTAL HEALTH PROBLEMS AND ILLNESS IN IRER GROUPS}

Studies conducted around the world point to increased rates of mental health problems and illnesses in refugee groups, some recent immigrant groups, and existing racialized and ethnocultural groups. Some of the factors driving increased risk of mental health problems and illnesses are common to these groups, such as unemployment, financial insecurity, poverty, and poor housing. Others, like pre-migration stress due to war, torture, and rape, and the stress of migration, will only impact some (Fornazzari \& Freire, 1990).

In Canada, there has been an increase in the last 20 years in research into the mental health of IRER groups; however, in comparison to other countries it is clear that there is still much that can be done. Although the research in Canada specific to IRER groups is of high quality, it only covers some groups and areas. Some 
regions (particularly Montreal, Toronto, and Vancouver) have extensive conducted and published research while other areas, including some entire provinces and territories, have none at all. In addition, research that is conducted on IRER groups tends to focus on the adult population. There is a growing literature on the mental health of seniors from IRER populations but there is an urgent need for more research into the rates of mental health problems and illnesses and the appropriate service response in children and youth. There is also a need for more research into those with intersectoral issues such as IRER groups with low income and the Lesbian, Gay, Bisexual, Transgender, Transsexual, Two-spirited, Inquiring, Queer, and Questioning (LGBTTTIQQ) population.

There is little Canadian research on initiatives at a policy or service level that would improve pathways to mental health care, care received, or outcomes for IRER groups.

Evaluating the findings of the research is complicated by inaccurate population counts and demographic differences between groups (Williams, 2001). In addition, diverse IRER groups are often lumped together as one population or they are grouped by major geographic region (e.g., Asia, Africa, or Europe). This blanket approach to categorization of groups may not be sufficiently fine-grained for the development of equitable services at a local level. For instance, there are major cultural, religious, historical, and language differences in people from Africa and these may be reflected in different needs at a service level.

Another barrier is that the published research tends towards quantitative methods even when qualitative methods may have provided a better exploration of the issues (Britten, 1995). This report will not discuss all of the research findings but will highlight primary findings from the research and illustrate them with specific papers.

In general research has focused on social factors associated with mental health problems in IRER groups, rates of mental illness, and barriers to and facilitators of care.

\section{Social Factors and Mental Health Problems}

The social determinants linked to developing mental health problems and illnesses may act on other interpersonal or social levels, for instance by undermining resiliency and coping networks. Social factors may over a life course contribute to the increase or decrease of someone's risk of developing a mental health problem or illness. Some increase vulnerability while others act as factors that precipitate illness. Some prolong illness and still others prevent illness and restore health. Vulnerability at specific transitions in life, such as during migration, are due to a significant increase in life stresses at a time when the social safety net may not be strong.

The Public Health Agency of Canada has produced a list of 12 determinants of health that are applicable to all (Public Health Agency of Canada, 2004). Research shows a greater negative involvement of these social determinants on IRER groups. In addition, the research offered perceived racial discrimination, migration, and language difficulties as novel social factors to which IRER populations are more likely to be exposed, factors linked to mental health problems.

There is a strong link between low income levels, income inequality, financial insecurity, poverty, and mental health problems and illness. Canada's IRER populations are more likely to be in the lower social 
classes and have lower-status jobs (Statistics Canada, 2001). A change in social status, particularly going from a higher status in the home country to a lower status in the host country, can also have a negative effect on mental health (Hyman, Forte, Du Mont, Romans, \& Cohen, 2006).

A significant problem for immigrant groups is the fact that social support networks may be broken and lost when people move (Berman et al., 2009). It takes considerable energy and time to reconstitute these networks, and although there is a history of immigrant groups organizing to provide support, this support may be limited compared to the extensive networks that have been left behind.

The proportion of people in IRER groups with university degrees is higher than the Canadian average (Statistics Canada, 2008c). Studies from around the world have shown that this does not translate into better mental health, and those with higher qualifications may do less well (Chen, Kazanjian, \& Wong, 2008); in fact, immigrants fare less well at work than people born in Canada despite their qualifications (Statistics Canada, 2008b). They earn less than their Canadian-born peers and are also more likely to live in low-income areas. Thirty per cent of immigrant men with university degrees work in occupations requiring only a high school diploma (Statistics Canada, 2008c).

Unemployment is more common for immigrants but even more so for immigrants who are also racialized (Statistics Canada, 2008d). Unemployed people experience higher levels of depression than those who are employed (Rodriguez, Frongillo, \& Chandra, 2001), since employment provides not only an income but also a sense of purpose and personal growth (Enang, 2001). Among employed IRER populations, a constant fear of becoming unemployed is a specific stressor (Ahmad et al., 2004).

People from IRER groups are more likely to live in poverty and to live in areas that are poor (Newbold, 2009). They are also more likely to live in cities and in areas with poor housing stock.

Healthy child development depends on time, community resources, and money. Over a third of immigrant children in Canada live in poverty. As a result of this, children are exposed to a significant number of social and environmental risks that can negatively impact their mental health. If a child is separated from their parents during the process of migration, they face an increased risk of a mental health problem or illness.

Migration is a particular stressor for immigrant groups. The process of migration and acculturation can be stressful and may increase risk for mental health problems and illness.

Perceived racial discrimination is a risk factor for mental health problems and illnesses more commonly experienced by IRER groups (Kafele, 2004). This is a complex social problem that has impacts at a number of different levels, from racial abuse or attack to more subtle forms such as stereotypes in the media. Perceived discrimination affects mental health through a direct effect on an individual's psychology and physiology as well as through its links to other social determinants of health (Noh et al., 2007).

There are over 200 languages spoken in Canada (Statistics Canada, 2006), and 20\% of the Canadian population have a mother tongue that is not English or French. When people develop mental health problems or illnesses they may need to use the language in which they can communicate best to explain what they are experiencing; indeed this may lead to better outcomes (Li \& Browne, 2000). The most common mother tongues apart from the official languages are Mandarin, Cantonese, and South Asian languages (Urdu, Hindi, and Punjabi). Fewer than half the people who speak these languages use English or French regularly at home. 


\section{Rates of Mental Illness}

Studies from around the world point to increased risk of mental health problems and illnesses in IRER groups (Cantor-Graae, Zolkowska, \& McNeil, 2005; Levecque, Lodewyckx, \& Vranken, 2007; Sharpley, Hutchinson, McKenzie, \& Murray, 2001). The rates of mental health problems and illnesses in IRER groups in Canada, however, are not consistently reported as elevated. Possible reasons for this include: (a) people with existing mental health problems and illnesses may be less likely to get through the immigration process, and (b) people who are recent immigrants may not disclose their mental health problems and illnesses.

The Canadian Community Health Survey (CCHS) offers one of the few national studies of mental illness in recent immigrants to Canada (Ali, 2002). It reported what is known as the "healthy immigrant effect." In this study, first-generation immigrants to Canada had lower rates of depression than Canadian-born residents; however, the CCHS also reported that rates of depression increase in the second generation. Similarly, it has been shown that second-generation young people in Canada engage in high-risk behaviours such as harmful drinking and illicit drug use more than first-generation young people (Hamilton, Noh, \& Adlaf, 2009).

Local studies do not always concur with the results of the CCHS; for instance, a study of adolescents in Quebec found high rates of psychopathology in refugee youth and a study of Toronto university students found that mild depression was more likely in South Asian and southern European students than in students of eastern European or Anglo-Celtic backgrounds (Tousignant, 1999). In Quebec, immigrant women belonging to minority groups were found to display higher depressive symptoms than women born in Canada or women from larger IRER groups, and a study of the Ethiopian-origin population in Toronto reported a lifetime prevalence rate of depression at 9.8\% (Fenta, Hyman, \& Noh, 2004), higher than the national average of between 7.9 and 8.6\% (Mood Disorders Society of Canada, 2009).

European studies show that immigrants, particularly African-Caribbean immigrants, are at an increased risk for schizophrenia and other psychoses. There is some suggestion of this found in studies in Nova Scotia (Kisely, Terashima, \& Langille, 1999) and Quebec (Tousignant, 1999), but no large-scale study has been conducted in Canada (McDermott et al., 2007).

As many as $2 \%$ of all deaths in Canada are by suicide (Statistics Canada, 2003). Research reports of immigrant groups place them in the lower risk range; however, studies of the mental health of Afghan youth note that almost $25 \%$ of the sample reported thoughts of suicide, and $16 \%$ of the total sample had attempted suicide.

It may be that the lack of clear findings at a national level reflects the heterogeneity of rates of mental illness in different groups. If some IRER groups have high rates of mental illness and others do not, then when averaged out, the different rates cancel one another. More fine-grained analysis may be needed.

Rates of mental health problems and illnesses do not give all the information required to develop services. This study was unable to find data on needs for mental health services for IRER groups at a national or at a local level. If services are to be built to meet the requirements of populations, then urgent information is required on mental health needs for IRER groups. 


\section{Barriers to and Facilitators of Care}

The need for services may be a more pertinent issue than the rates of mental illness show. Groups exposed to significant life events and social stress, low incomes, fractured support networks, and poor societal safety nets may be more likely to move from the development of symptoms to needing to use mental health services. IRER groups are more likely to be exposed to social determinants that promote mental health problems and illnesses at a time when community and personal resources that support individuals and promote health are diminished.

Most people in need of mental health care do not get it, however. Studies raise concerns about access to mental health services for IRER groups and the care that is received (Lai \& Chau, 2007).

Immigrants are less likely than their Canadian counterparts to use a mental health service in primary care or specialty settings (Kirmayer et al., 2007). A study by Whitley, Kirmayer, \& Groleau (2006) found that some of the barriers to seeking treatment include a perception of a doctor's over-willingness to prescribe medication, the interaction between the patient and doctor, and a stronger belief in traditional therapies. Studies reported that mainstream mental health care was considered inconsistent with the values, expectations, and patterns of help-seeking IRER groups. The incompatibility between services and Black women (Women's Health Matters, 2007), South Asian women, Tamil and Asian seniors (Lai \& Chau, 2007), and West Indian immigrants (Schreiber, Stern, \& Wilson, 1998) have been documented, for example. Those who are more educated tend to be more likely to seek services for their mental health problems and illnesses (both in IRER populations and non-IRER populations).

Language was often cited in the Canadian literature as a barrier to care (Sadavoy, Meier, \& Ong, 2004; Wang, 2007). This is partly because many cannot use services unless there is interpretation but also because it is difficult to know what services are available. Although interpreter services are mandated in the court system, they are rarely available in the health system. Even if language services were fully available, some might question whether the same quality of treatment could be delivered through an interpreter.

There are reports that some from IRER groups are either not aware of the services that are available to them or do not understand how the health care system works. A lack of knowledge about where to get care was reported as an impediment by Afghani and Asian Canadians (Li \& Browne, 2000), and poor information about available services was reported by Chinese immigrants (Chen \& Kazanjian, 2005).

Socioeconomic barriers differentially affect IRER groups in Canada as these groups are more likely to be poor. Low income decreases access to and utilization of health care services. Several provinces impose a 3-month delay after arrival into Canada to receive health insurance, and certain categories of temporary workers, foreign students, visitors, and undocumented migrants are excluded from provincial health coverage (Oxman-Martinez et al., 2005). Services are often only available during the week, and this may act as a barrier for someone who is employed. Transportation costs can also impact service use. In addition, a lack of funds can prevent people from purchasing necessary medications. This means that people may not be able to afford any or all of their medications, which will further prevent treatment.

Studies of both Asian Canadians (Li \& Browne, 2000) and Black women (Enang, 2001) cited perceived racial discrimination as a barrier to care. Institutionalized discrimination has been a way of considering structural barriers to accessing mental health care by IRER groups. The argument has not been that practitioners 
directly and actively discriminate against particular groups but that the system of care works to offer poorer access and treatment to these groups. One-size-fits-all services ignore the differential needs, presentation of problems, and desires of groups, all of which can lead to poorer outcomes (Georgiades, Boyle, \& Duku, 2007; Li \& Browne, 2000).

The stigma of mental illness and of accessing mental health services is a significant barrier to care. Although misperceptions and stigma can be seen in all societies, there are some communities that experience a deeper level of stigma than others (Yee, 2006). In some communities, acknowledging a mental health problem can bring significant shame not just to the individual but to the entire family (Schreiber et al.,1998).

Some literature exists reporting factors that facilitate people from IRER groups in Canada getting care. In the Tamil population, for instance, this includes length of stay in Canada, trust in the system, knowledge and education, and cultural competency. In Southeast Asian university students, acculturation and cooperation between service providers has been reported as helpful, and in the Somali community ethnospecific health promotion and diversity of services, including alternative approaches, have been cited (Elmi, 1999).

\section{POLICY PAPERS ON IMPROVING MENTAL HEALTH SERVICES FOR IRER POPULATIONS}

\section{The Response of the Provinces and Territories}

Provinces and territories have the primary responsibility for delivering mental health services. The architecture of services, organization of funding, planning, and governance varies. Similarly there has been a variety of responses to the challenges of developing mental health service for IRER populations.

All provinces were contacted for the purpose of this study. They reported 66 services or initiatives specifically targeted at IRER groups to improve services and outcomes for people with mental health problems and illness. No province, territory, or region had linked organizational cultural capability to direct-service provision or to evaluation of outcomes.

Improving the mental health of IRER groups is complex and the impact of the social determinants of health requires significant planning, cross-sectoral support, and political will. This project was unable to identify any province, territory, or region with a comprehensive strategy for improving the mental health of IRER populations.

\section{The Federal Response: After the Door Has Been Opened}

The mental health of immigrant populations has been of interest to the federal government for many years, and a national task force was established in the mid-1980s to investigate the issue. Their findings were reported as After the Door Has Been Opened in 1988 (Canadian Task Force on Mental Health, 1988). The task force concluded that although moving from one country and culture to another inevitably entails stress, it does not necessarily have to threaten mental health. The mental health of immigrants and refugees becomes a concern primarily when additional risk factors combine with the stress of migration. One of the main issues this report describes is that immigrants and refugees do not have a voice in the mental health care system from the point of view either of people living with mental health problems or illnesses or of service providers. 
The task force offered 27 recommendations for Citizenship and Immigration Canada, Health Canada, and other federal bodies to improve mental health for immigrant groups. As of 2009, only six of the recommendations had been implemented in full.

Although Health Canada was named in the recommendations, it explained to this research team that it has difficulty enforcing or contributing to them because it is a federal body that does not actively deal with service delivery. Provincial health departments are responsible for services for IRER populations.

\section{The Senate Report: Out of the Shadows at Last}

The Senate report Out of the Shadows at Last (Kirby \& Keon, 2006) reported on mental health services for refugee and immigrants some 18 years after the task force report After the Door Has Been Opened. It reinforced the expectation that, after admission to Canada, the delivery of public health programs and services related to mental health is a responsibility of the provinces and territories.

The report called for Canada's commitment to provide safe refuge to include assurances that individuals have access to health services to help them with any mental health problems they face. It identified a role for an external body to provide oversight and assessment of how well the federal government is meeting its commitments to immigrants and refugees. It recommended

That the federal government establish an entity for immigrants and refugees, similar to the Correctional Investigator, the Canadian Forces Ombudsman, or the RCMP External Review Committee;

That this entity be authorized to investigate individual complaints as well as systemic areas of concern related to federal provision of programs and services that have an impact on the mental wellbeing of immigrants and refugees;

That this entity provide an annual report to Parliament. (Kirby \& Keon, 2006, p. 346)

The report also supported the greater involvement of immigrant and refugee communities as partners in research, program development, and service delivery. It argued that there is a need for more Canadian research into the identification and evaluation of culturally appropriate systems of care for immigrant populations, particularly in relation to vulnerable populations such as children, women, and seniors.

\section{A STRATEGY FOR SERVICE DEVELOPMENT}

Canada's population is becoming more diverse with some regions' IRER populations increasing significantly each year. Mental health services will need to reflect these population shifts. Several issues have been raised, including the social determinants of health, differences in rates of mental health problems and illnesses, barriers to care, and need for services. Key concerns centre on the mental health impacts of unemployment, underemployment, low income, language difficulties, social isolation, migration, and discrimination. Children and the elderly also require special attention.

The issues are complex. Canadian literature on mental health, mental health problems and illnesses, and service needs of IRER populations is not extensive, but what there is indicates that socio-environmental factors may increase the risk of mental health problems and illnesses over time in some IRER groups. A significant body of research details the barriers that IRER groups face to receiving good-quality care, indicating that these groups are more likely to be underserved. Language is a particular barrier to care. 
There has been some consideration of refugee and new immigrant groups but no concerted effort at a national level to consider the needs of existing racialized and ethnocultural groups.

There is little Canadian research on initiatives at a policy, service, or educational level that could improve the mental health of, or mental health care for, IRER groups. The international literature could offer some direction, however (National Institute for Mental Health in England, 2003; U.S. Department of Health and Human Services, 2001).

Improving mental health will require action across a number of sectors, including private and voluntary sectors as well as a range of public organizations - not just traditional health services. The goal should be to promote strong and healthy communities and build resiliency rather than just to improve services.

One approach would be to involve IRER communities in the development of population-based, flexible services that understand and meet their needs. Using such an approach, provinces, territories, and regions would be able to tailor service development to their demographic imperatives. In addition, the experience of local communities could be employed to help develop services that are suitable for the people who are likely to use them.

Three intertwined groups of actions may help deliver such a strategy:

1. Coordination of policy, knowledge, and accountability;

2. The involvement of communities, families, and consumers;

3. More appropriate and improved services.

The bidirectional arrows on the diagram (Figure 2) indicate that this is an iterative process.

Figure 2

Actions to Help Deliver a Strategy Involving IRER Communities

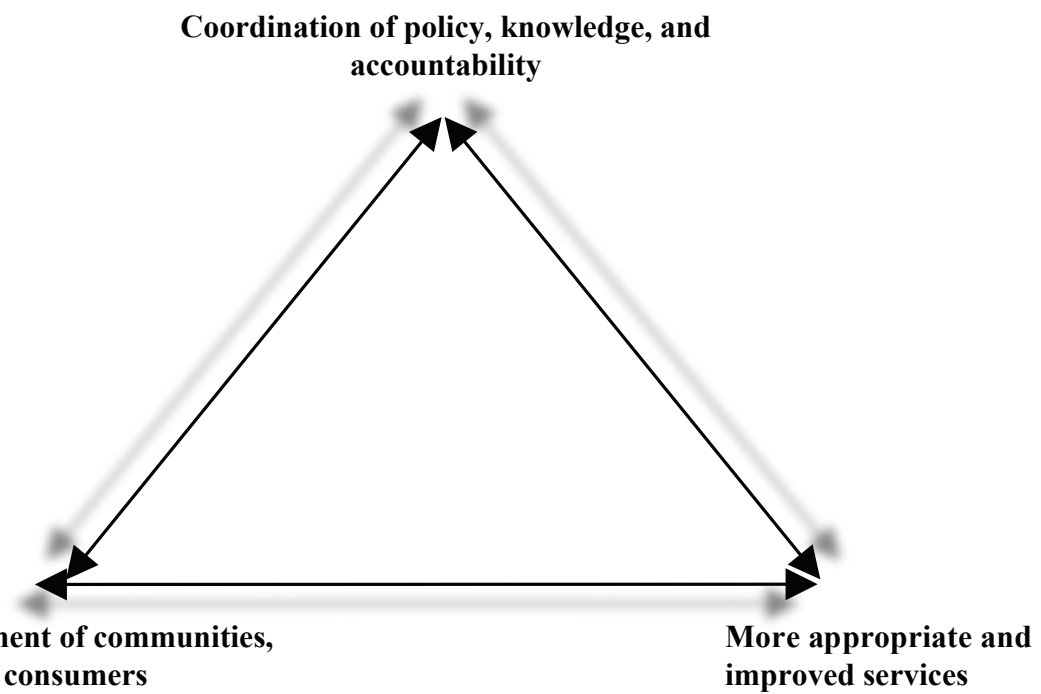

The involvement of comm
families, and consumers

improved services 


\section{Coordination of Policy, Knowledge, and Accountability}

Policy development is needed on at least two fronts, to improve the mental health and decrease the risk of mental health problems and illness in IRER groups, and to improve services for IRER people with mental health problems and illnesses.

The evidence showing the importance of the social determinants of health argues for a more fundamental need to develop initiatives that decrease individual and community exposure to factors that harm mental health and increase the risk of mental health problems and illnesses as well as developing efforts to improve communities and build resiliency. Such efforts will need to include the private and voluntary sectors as well as those involved in developing mental health, public health, and social policy. The accountability for this is diffuse and lies with a number of government departments at different levels. Despite agreement across provinces on the direction or goals of a mental health service, the delivery of new services will be the responsibility of individual provinces, territories, and regions. Effective leadership and liaison between these groups will be important if a coordinated public health approach is to be taken. This will require a whole-ofgovernment approach rather than siloed approaches, and consideration of place-based policy and strategy.

During our study we discovered many services that try to offer care to IRER groups. In some areas there were both mainstream services and ethnospecific services offering mental health care, but these were not coordinated in any meaningful way. The focus was on getting a service running and treating people rather than taking the time to plan a targeted service. Some were offering high-quality care to those able to access their services but most people were not that fortunate.

For there to be effective service development so that the largest numbers of people are reached, there needs to be coordination and a strategy leading to a plan backed up by a data stream and evaluation. Making sure the plan works requires a framework of accountability and monitoring. The alignment of plans at different levels of federal, provincial, and regional jurisdiction would bring the best results but may be difficult to achieve; provincial and local alignment may be more possible. Clearly, the benefit of coordinated plans is that they can increase productivity and decrease duplication. Plans that aim to integrate different service providers and sectors of care and aim to consider services in other sectors linked to health, such as settlement services, will be most effective. A plan at any level, even if it is not coordinated, will be better than none, however.

A plan can have other benefits. The process of developing a plan can be used as an initiative for developing partnerships and networks, uncovering local good practice, and building capacity, as well as delivering a blueprint for service improvement. Plans would be best built on local information. Some data are available from routine sources and from the census, but in many places there may need to be an initiative to develop the knowledge base.

In an evidence-based system, information is the building block of services and also a way of monitoring success. The lack of data on the gaps in mental health services and the use of mental health services by IRER groups undermines the ability to plan care. For instance, most IRER groups have an age distribution skewed towards youth, but in the next two decades this demographic will age. In addition, there was a significant increase in migration from non-European countries from the 1960s onwards. These groups are getting older and increasing the population that may be in need of psychiatric services for IRER seniors. Plans may want to target early treatment and prevention in youth but not leave out the demographic of the aging population, 
which may bring more Canadians with different needs, cultures, traditions, and languages into contact with old age mental health and care services.

Quantitative data are important, but qualitative data will be needed to capture experiences that cannot be represented by numbers alone. The quality of the data may be improved if IRER groups are involved in all aspects of knowledge development, from the design of the investigation to its analysis and presentation. Data by themselves do not change services. To make a difference, the data will need to be used intelligently and drawn on by those who make policy as well as those who plan and operate services.

Given the complexities, some areas may not have the expertise to analyze cross-cultural data, or to consider what the literature reports concerning appropriate service models or risks. One solution to this issue would be to develop an independent, national group of experts that includes members of IRER communities to provide technical assistance. This could be done in a virtual centre using existing expertise from across Canada. Such a centre would need to be linked to the community as well as to academic expertise. Another role for this group might be to help areas produce the data on local needs required to develop their plan.

The development of knowledge about the diversity of the community served and the resulting data around access to services and service usage can help service providers to consider the most appropriate service developments and plans and help funding bodies ensure that their diverse communities are being served. A framework for accountability and feedback will be required to ensure that plans are implemented as expected.

Across Canada ad hoc services are being developed without a clear plan and without data. Excellent services have been produced in this way, but it is not clear that these services formed a coherent response to the need in their respective areas. The process of planning used creatively, moreover, can bring about lasting change in relationships, resulting in beneficial architecture for future development and interactions with IRER groups in other spheres.

\section{Involving Communities, Families, and Consumers}

Improving mental health services relies not only on data and knowledge of demographics but also on understanding a population's views about service delivery. Knowing the views of all stakeholders can improve the efficacy of services. Communities and people with lived experience should be included in the decision-making process as they may have differing ideas about who should be offering services, where they should be offered and how they should be best configured. Services are increasingly moving towards models that consumers and families have had an important voice in configuring.

At another level, engaging better with communities can decrease duplication of services and offer new and more efficient models of service delivery. Diversifying models of care through the encouragement of local ethnospecific solutions to challenges could offer an adjunct to an improved response of mainstream service; the aim would be to harness the expertise of communities, increase community efficacy, and improve the local safety net.

Developing networks of consumers, family members, and community representatives who are interested in the improvement of the service response is an important step. The network can act as a conduit for knowledge exchange about needs, services that are available, and problems with accessing services. Including 
diverse communities can help to determine the needs of particular groups, for instance LGBTTTIQQ. Specific processes to ensure all voices are heard are paramount.

A lack of awareness of services was a recurrent theme during our consultations. In this information age we need to consider knowledge transfer. Not only do services need to be better informed about communities but the process can be used to increase the awareness of communities about existing services.

\section{Better and More Appropriate Services}

A plan, local knowledge, and the involvement of the community are prerequisites for the development of more appropriate services. The actions required to improve mental health services for IRER populations can be considered in five groups, and they work in concert to produce services that are capable of meeting IRER needs: changed focus, improvement within services, improved diversity of treatment, linguistic competence, and needs linked to expertise.

Changed focus. In addition to policy development aimed at decreasing negative impacts related to social determinants of health, and specific risk factors such as the impact of migration, racial discrimination, and language barriers that affect IRER groups, the focus of service will need to change to embrace health promotion and illness prevention.

Promotion efforts that focus on IRER groups can be effective in improving pathways to care and decreasing exposure to risks. During the consultations, some participants stated that stigma was a particular problem in some IRER groups and that specific targeted anti-stigma campaigns would be an important facet of any strategy. Groups such as youth could be offered opportunities for creative health promotion and prevention strategies; for example, it was recommended that youth in the Somali community could be trained in mental health as a way of raising family and community awareness.

Improvement within services. There was general agreement in the consultations that improving services to meet the needs of IRER groups might be easier if a diverse workforce reflects the population it serves. For progress to be made, improved representation is needed at all levels, including the leadership of both purchasers and providers of care.

In addition to improving the diversity of staff and developing leadership there will need to be organizational strategies for cultural competence leading to an improved understanding of the community and an environment in which more appropriate services can flourish. Organizational cultural competence will be reflected in the working environment, the policies of the organization, including race relations, and attention to the minimization of structural barriers to care through the development of an active network of community partners. Direct care staff and others who come in contact with the IRER population also need to be more culturally capable.

There is a vast literature on training to improve cultural awareness and competence, with evidence that training can change attitudes, knowledge, and skills when treating people from IRER groups (Fung, Andermann, Zaretsky, \& Lo, 2008; Bhui, Warfa, Edonya, McKenzie, \& Bhugra, 2007). There are few data on whether it changes outcomes, however. Two factors are involved here: that outcomes are not measured, and that for knowledge, attitudes, and skills to be translated into better outcomes we need organizational structure that allows and supports practice change. 
Participants in the consultations strongly endorsed training to improve the capacity of service providers to meet the needs of diverse IRER groups, but it should be made clear that training in the absence of service and organizational development strategies that support inclusion and diversity is unlikely to improve the experience of mental health services for IRER groups. In a situation where an IRER group has problems accessing hospital-based services because of their location or because of a lack of awareness, for instance, staff training is unlikely to make a significant difference to clients who lack basic access. It is also important to note that there are many forms of training, and assessment of these has mainly been outside Canada. There is no consensus currently on the best forms of training to meet the specific social context, levels of immigration, history of immigration, and diversity of IRER groups in Canada.

Improved diversity of treatments, providers, and institutions. The issue of the need for more diversity in mental health service provision has been a clear theme of the research and our consultations. The health care sector needs to recognize, understand, and respect different cultural groups' models of care. Out of the Shadows at Last calls for a better understanding of strategies that work in IRER mental health and a dissemination of that knowledge. Models of care that include cultural interpretation services and cultural liaison services have been developed and may offer one service response. Across Canada, same-language services and IRER service providers exist in pockets. In addition, some communities have expressed the wish for services to be where people have better access to them, such as one-stop centres and mall-based mental health services as well as services for children in guidance offices at school. Given the diversity of the IRER population and the differences in demographic changes and urgency in different areas there is unlikely to be a one-size-fits-all solution to service models. Knowledge about the development and evaluation of different service models would benefit planners when deciding what is possible in their area.

Linguistic competence. Language issues present a barrier to good care. As noted previously, approximately 6.2 million Canadians do not speak English or French as their mother tongue. Given this, the development of a comprehensive linguistic competence strategy is a clear target for service improvement, the breadth and balance of which may be different in different areas depending on need. Language supports at a number of levels could be offered, including a plain-language strategy for those who speak English or French, and interpretation, translation, and cultural interpretation services for those who speak other languages. Signage, documentation, and information leaflets should be translated to meet the needs of the population. Although these services are available in the legal system, very few jurisdictions in Canada provide them in health or mental health services.

Such strategies may lead to a need for training for practitioners on how to work with interpreters. Interpreters themselves may need training in mental health and accreditation, and bilingual practitioners will need to be supported. In some instances, ancillary services such as tele-interpreting may be of use.

Linking needs to expertise. Because of the variety and differing percentages of IRER groups across the country, some believe that the development of specific services is neither possible nor strategically important. The challenge is how to offer high-quality services in areas where there are few people from IRER groups. One strategy would be for more populous regions or areas with expertise to partner with areas with low concentrations of IRER groups. Centres of excellence could offer satellite services or clinics, and IRER groups could also be offered an option of same-language services via telemedicine. 
Existing e-health resources and techniques, including online treatment and education, could be developed to make them more accessible to IRER groups. Strategies should be developed that are not dependent on access to a computer but can leverage phone or smartphone technology. The central aim in all of this is to link people to the right information and expertise, and to link organizations with the expertise to those who may find it difficult to offer services because their populations are too small for quality services to be developed and sustained.

\section{CONCLUSION}

The "Issues and Options" paper suggests that the major plank of any initiative to improve mental health, decrease the risk of developing mental health problems and mental illness, and improve the outcomes of care for IRER groups is the development of a plan based on population-level data and knowledge about the needs of communities that are served. The suggested plan for service improvement focused on policy improvement and public health interventions aimed at health promotion and illness prevention. The exact extent of the plan depends on the needs of the population and resources available. Including IRER population groups in the planning helps in the development of more appropriate services and also allows for linkage to community-based services, decreasing duplication, and increasing the diversity of services, leading to improved awareness and access. With data and community connections, services can forge a path of internal development that includes training and organizational change to facilitate clinicians using their knowledge, attitudes, and skills concerning cultural competence and promoting access and partnerships. Across Canada, pockets of good practice exist, although we were unable to find any province, territory, or region whose respondents said they were effectively meeting the service needs of IRER populations at a systems level.

The implication of the evidence-based approach of "Issues and Options" is that further work will always be needed to ensure that healthy equity interventions meet their target. There are always issues that may need revisiting. In general there is a need for up-to-date and updated statistics on the social risk factors to IRER populations and how these change over time. External factors may apply to different generations in different ways. As Canadian immigration changes, the percentage of people with pre-immigration trauma may change and this needs to be taken into account. Community level resilience, both our understanding of it and its impact, will need to be monitored along with the availability of material support in a changing labour market that puts particular pressures on family members. "Issues and Options" offers the information available at the time of writing, and making the case for diversity will move the debate forward.

\section{REFERENCES}

Ahmad, F., Shik, A., Vanza, R., Cheung, A. M., George, U., \& Stewart, D. E. (2004). Voices of South Asian women: Immigration and mental health. Women Health, 40, 113-130.

Ali, J. (2002). Mental health of Canada's immigrants. Supplement to Health Reports, 13. Statistics Canada, Cat. no. 82003. Ottawa, ON: Statistics Canada.

Berman, H., Mulcahy, G., Forchuk, C., Edmunds, K., Haldency, A., \& Lopez, R. (2009). Uprooted and displaced: A critical narrative study of homeless, Aboriginal, and newcomer girls in Canada. Issues in Mental Health Nursing, $30,418-430$.

Bhui, K., Warfa, N., Edonya, P., McKenzie, K., \& Bhugra, D. (2007). Cultural competence in mental health care: A review of model evaluations. BMC Health Services Research, 7, 15. 
Britten, N. (1995). Qualitative interviews in medical research. BMJ, 311, 251-253.

Canadian Task Force on Mental Health. (1988). After the door has been opened: Mental health issues affecting immigrants and refugees in Canada. Ottawa, ON: Author.

Cantor-Graae, E., Zolkowska, K., \& McNeil, T. F. (2005). Increased risk of psychotic disorder among immigrants in Malmö: A 3-year first-contact study. Psychological Medicine, 35, 1155-1163.

Chen, A. W., \& Kazanjian, A. (2005). Rate of mental health service utilization by Chinese immigrants in British Columbia. Canadian Journal of Public Health, 96, 49-51.

Chen, A., Kazanjian, A., \& Wong, H. (2008). Determinants of mental health consultations among recent Chinese immigrants in British Columbia, Canada: Implications for mental health risk and access to services. Journal of Immigrant and Minority Health, 10, 529-540.

Elmi, A. (1999). A study on the mental health needs of the Somali community in Toronto. Toronto, ON: York Community Services and Rexdale Community Health Centre.

Enang, J. (2001). Black women's health: A synthesis of health research relevant to Black Nova Scotians. Halifax, NS: Maritime Centre of Excellence for Women's Health. Retrieved from http://www.dal.ca/content/dam/dalhousie/ pdf/ace-women-health/ACEWH_health_research_relevant_to_black_nova_scotian_women.pdf

Fenta, H., Hyman, I., \& Noh, S. (2004). Determinants of depression among Ethiopian immigrants and refugees in Toronto. Journal of Nervous and Mental Disease, 192, 363-372.

Fornazzari, F., \& Freire, M. (1990). Women as victims of torture. Acta Psychiatrica Scandinavica, 82, $257-260$.

Fung, K., Andermann, L., Zaretsky, A., \& Lo, H. T. (2008). An integrative approach to cultural competence in the psychiatric curriculum. Academic Psychiatry, 32, 272-282.

Georgiades, K., Boyle, M. H., \& Duku, E. (2007). Contextual influences on children's mental health and school performance: The moderating effects of family immigrant status. Child Development, 78, 1572-1591.

Hamilton, H. A., Noh, S., \& Adlaf, E. M. (2009). Adolescent risk behaviours and psychological distress across immigrant generations. Canadian Journal of Public Health, 100, 221-225.

Hyman, I., Forte, T., Mont, J. D., Romans, S., \& Cohen, M. M. (2006). The association between length of stay in Canada and intimate partner violence among immigrant women. American Journal of Public Health, 96(4), 654-659. doi:10.2105/AJPH.2004.046409

Kafele, K. (2004). Racial discrimination and mental health in racialized and Aboriginal communities. Toronto: Ontario Human Rights Commission. Retrieved from http:/www.ohrc.on.ca/en/race-policy-dialogue-papers/ racial-discrimination-and-mental-health-racialized-and-aboriginal-communities

Kirby, M. J. L., \& Keon, W. J. (2006). Out of the shadows at last: Transforming mental health, mental illness and addiction services in Canada. Ottawa, ON: Standing Senate Committee on Social Affairs, Science and Technology. Retrieved from http://www.parl.gc.ca/content/sen/committee/391/soci/rep/pdf/rep02may06part1-e.pdf \& http:// www.parl.gc.ca/content/sen/committee/391/soci/rep/pdf/rep02may06part2-e.pdf

Kirmayer, L. J., Weinfeld, M., Burgos, G., du Fort, G. G., Lasry, J. C., \& Young, A. (2007). Use of health care services for psychological distress by immigrants in an urban multicultural milieu. Canadian Journal of Psychiatry, 52, 295-304.

Kisely, S., Terashima, M., \& Langille, D. (2008). A population-based analysis of the health experience of African Nova Scotians. Canadian Medical Association Journal, 179, 653-658.

Lai, D., \& Chau, S. (2007). Effects of service barriers on health status of older Chinese immigrants in Canada. Social Work, 52(3), 261-269.

Levecque, K., Lodewyckx, I., \& Vranken, J. (2007). Depression and generalised anxiety in the general population in Belgium: A comparison between native and immigrant groups. Journal of Affective Disorders, 97, $229-239$.

Li, H. Z., \& Browne, A. J. (2000). Defining mental illness and accessing mental health services: perspectives of Asian Canadians. Canadian Journal of Community Mental Health, 19, 143-159.

McDermott, S., Dealberto, M. J., DesMeules, M., Kazanjian, A., Manuel, D., Ruddick, E., \& Vissandjee, B. (2007, November 15). Psychoses-related acute hospital discharges among immigrants arriving to Canada between 1985 and 2000: A linkage follow-up study using administrative data. In Proceedings of the Canadian Academy of Psychiatric Epidemiology conference, Montreal, Quebec. 
Mood Disorders Society of Canada. (2009). Quick facts: Mental illness and addiction in Canada (3rd ed.). Guelph, ON: Author. Retrieved from http://www.mooddisorderscanada.ca/documents/Media Room/Quick Facts 3rd Edition Eng Nov 12 09.pdf

National Institute for Mental Health in England. (2003). Inside outside: Improving mental health services for Black and minority ethnic communities in England. Leeds, England: Author.

Newbold, B. (2009). The short-term health of Canada's new immigrant arrivals: Evidence from LSIC. Ethnicity \& Health, 14, 315-336.

Noh, S., Kaspar, V., \& Wickrama, K. A. (2007). Overt and subtle racial discrimination and mental health: Preliminary findings for Korean immigrants. American Journal of Public Health, 97, 1269-1274.

Oxman-Martinez, Hanley, J., Lach, L., Khanlou, N., Weerasinghe, S., \& Agnew, V. (2005). Intersection of Canadian policy parameters affecting women with precarious immigration status: A baseline for understanding barriers to health. Journal of Immigrant and Minority Health, 7(4), 247-258.

Public Health Agency of Canada. (2004). The social determinants of health: An overview of the implications for policy and the role of the health sector. Retrieved from http://www.phac-aspc.gc.ca/ph-sp/oi-ar/pdf/01_overview_e.pdf

Rodriguez, E., Frongillo, E. A., \& Chandra, P. (2001). Do social programmes contribute to mental well-being? The long-term impact of unemployment on depression in the United States. International Journal of Epidemiology, 30, 163-170.

Sadavoy, J., Meier, R., \& Ong, A. Y. (2004). Barriers to access to mental health services for ethnic seniors: The Toronto study. Canadian Journal of Psychiatry, 49, 192-199.

Schreiber, R., Stern, P. N., \& Wilson, C. (1998). The contexts for managing depression and its stigma among Black West Indian Canadian women. Journal of Advanced Nursing, 27, 510-517.

Sharpley, M., Hutchinson, G., McKenzie, K., \& Murray, R. M. (2001). Understanding the excess of psychosis among the African-Caribbean population in England: Review of current hypotheses. British Journal of Psychiatry Suppl, 40, s60-s68.

Statistics Canada. (2001). Selected income characteristics (35), age groups (6), sex (3) and visible minority groups (15) for population, for Canada, provinces, territories and Census Metropolitan Areas, 2001 census, 20\% sample data [table]. In 2001 census topic-based tabulations: Ethnocultural portrait of Canada. Statistics Canada Cat. no. 97F0010XCB2001047. Ottawa, ON: Author. Retrieved from http://www12.statcan.gc.ca/english/ census01/products/standard/themes/Rp-eng.cfm?LANG=E\&APATH=3\&DETAIL=1\&DIM=0\&FL=A\&FREE $=$ $0 \& \mathrm{GC}=0 \& \mathrm{GID}=0 \& \mathrm{GK}=0 \& \mathrm{GRP}=1 \& \mathrm{PID}=68640 \& \mathrm{PRID}=0 \& \mathrm{PTYPE}=55430,53293,55440,55496,71090 \& \mathrm{~S}=0 \&$ SHOWALL $=0 \& S U B=0 \&$ Temporal $=2001 \&$ THEME $=44 \& V I D=0 \& V N A M E E=\& V N A M E F=$

Statistics Canada, (2003). Causes of death: chapter XX: External causes of morbidity and mortality (V01 to Y89), by age group and sex, Canada. Statistics Canada Cat. no. 84-208-XIE. Ottawa, ON: Author. Retrieved from http:// www.statcan.gc.ca/pub/84-208-x/2005002/t/4200026-eng.pdf

Statistics Canada (2006). The evolving linguistic portrait, 2006 census. Statistics Canada Cat. no. 97-555-XIE. Ottawa, ON: Author. Retrieved from http://www12.statcan.gc.ca/english/census06/analysis/language/pdf/97555-XIE2006001.pdf

Statistics Canada. (2008a). Canada's ethnocultural mosaic, 2006 census. Statistics Canada Cat. no. 97-562-X. Ottawa, ON: Author. Retrieved from http:/www12.statcan.ca/english/census06/analysis/ethnicorigin/pdf/97-562XIE2006001.pdf

Statistics Canada. (2008b). Earnings and incomes of Canadians over the past quarter century, 2006 census. Statistics Canada Cat. no. 97-563-X. Ottawa, ON: Author. Retrieved from http://www12.statcan.ca/english/census06/ analysis/income/pdf/97-563-XIE2006001.pdf

Statistics Canada. (2008c). Educational portrait of Canada, 2006 census. Statistics Canada Cat. no. 97-560-X. Ottawa, ON: Author. Retrieved from http://www12.statcan.ca/english/census06/analysis/education/pdf/97-560XIE2006001.pdf

Statistics Canada. (2008d). Population groups (28), age groups (8), sex (3), and selected demographic, cultural, labour force, educational and income characteristics (309), for the total population of Canada, provinces, territories, Census Metropolitan Areas and Census Agglomerations, 2006 census, 20\% sample data [table]. In 2006 census: Data products: Special interest profiles: Ethnic origin and visible minorities. Statistics Canada Cat. no. 97564X2006009. 
Ottawa, ON: Author. Retrieved from http://www12.statcan.gc.ca/census-recensement/2006/dp-pd/prof/sip/ Rp-eng.cfm?LANG $=\mathrm{E} \& A P A T H=3 \& \mathrm{DETAIL}=0 \& \mathrm{DIM}=0 \& \mathrm{FL}=\mathrm{A} \& \mathrm{FREE}=0 \& \mathrm{GC}=0 \& \mathrm{GID}=0 \& \mathrm{GK}=0 \& \mathrm{GRP}=$ $1 \& \mathrm{PID}=97615 \& \mathrm{PRID}=0 \& \mathrm{PTYPE}=97154 \& \mathrm{~S}=0 \& \mathrm{SHOWALL}=0 \& \mathrm{SUB}=0 \& \mathrm{Temporal}=2006 \& \mathrm{THEME}=80 \& \mathrm{~V}$ $\mathrm{ID}=0 \& \mathrm{VNAMEE}=\& \mathrm{VNAMEF}=$

Tousignant, M. (1999). The Quebec adolescent refugee project: Psychopathology and family variables in a sample from 35 nations. Journal of the American Academy of Child and Adolescent Psychiatry, 38(11), 1426-1432.

U.S. Department of Health and Human Services. (2001). Mental health: Culture, race, and ethnicity-a supplement to Mental health: A report of the Surgeon General. Rockville, MD: U.S. Department of Health and Human Services, Substance Abuse and Mental Health Services Administration, Center for Mental Health Services.

Wang, L. (2007). Ethnicity, spatial equity, and utilization of primary care physicians: A case study of Mainland Chinese immigrants in the Toronto CMA. Toronto, ON: CERIS-Metropolis Centre.

Whitley, R., Kirmayer, L. J., \& Groleau, D. (2006). Understanding immigrants' reluctance to use mental health services: A qualitative study from Montreal. Canadian Journal of Psychiatry, 51, 205-209.

Williams, C. (2001). Increasing access and building equity into mental health services: An examination of the potential for change. Canadian Journal of Community Mental Health, 20, 37-51.

Women's HealthMatters.(2007). Howbeing Blackandfemaleaffectsyourhealth (Women's HealthMatters article). Toronto, ON: Women's College Hospital. Retrieved from http:/www.womenshealthmatters.ca/health-centres/health-information/ resources/feature-article/how-being-black-and-female-affects-your-health-(womens-health-matters-article)

Yee, J. (2006). Striving for best practices and equitable mental health care access for racialised communities in Toronto. Toronto, ON: Access Alliance. Retrieved from http://accessalliance.ca/wp-content/uploads/2015/03/ EquitableMentalHealthCareAccessResearchReport.pdf 